\title{
Sealing Carious Fissures with Resin Infiltrant in Association with a Flowable Composite Reduces Immediate Microleakage?
}

\author{
Vanessa Brígido da Silva ${ }^{1}$, Raquel Nogueira de Carvalho1@ ${ }^{1}$, Tamiris Gomes Bergstrom ${ }^{\circledR}$, Thais

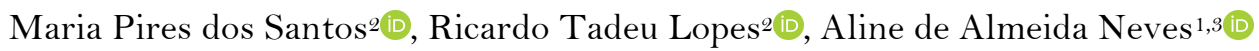

\begin{abstract}
${ }^{1}$ Department of Pediatric Dentistry and Orthodontics, School of Dentistry, Federal University of Rio de Janeiro, Rio de Janeiro, RJ, Brazil.

${ }^{2}$ Laboratory of Nuclear Instrumentation, Federal University of Rio de Janeiro, Rio de Janeiro, RJ, Brazil.

${ }^{3}$ Faculty of Dentistry, Oral \& Craniofacial Sciences, King's College London, London, United Kingdom.
\end{abstract}

Author to whom correspondence should be addressed: Dr. Aline de Almeida Neves, Federal University of Rio de Janeiro, School of Dentistry, Department of Pediatric Dentistry and Orthodontics, Rio de Janeiro, RJ, Brazil. 21941-971. Phone: +55 22 99939-7714. E-mail: alineves@ufrj.br.

Academic Editors: Alessandro Leite Cavalcanti and Wilton Wilney Nascimento Padilha

Received: 12 August 2019 / Accepted: 23 March 2020 / Published: 14 April 2020

\footnotetext{
How to cite this article: Silva VB, Carvalho RN, Bergstrom TG, Santos TMP, Lopes RT, Neves AA. Sealing carious fissures with resin infiltrant in association with a flowable composite reduces immediate microleakage?. Pesqui Bras Odontopediatria Clín Integr. 2020; 20:e5114. https://doi.org/10.1590/pboci.2020.067
}

\begin{abstract}
Objective: To compare the immediate microleakage of carious fissures sealed with a caries infiltrant covered by a flowable composite or solely with a flowable composite. Material and Methods: Extracted carious molars $(n=20)$ were selected and paired among the experimental groups according to caries progression scores. Experimental groups $(n=10)$ were divided according to the following sealing techniques: 1) caries infiltrant (Icon) + flowable composite (Z350 flow); 2) flowable composite (Z350 flow). Specimens were immersed in $3 \%$ methylene blue and evaluated in a stereomicroscope. Microleakage scores were attributed independently by two calibrated evaluators and the mode value was considered as the mean for the specimen. Binomial tests were used to test differences between two independent sample proportions at $5 \%$ significance level. Results: In the flowable composite group, a higher prevalence of dye penetration along the full depth of the fissure was observed, compared with caries infiltrant + flowable composite $(\mathrm{p}<0.05)$. For specimens showing dye penetration up to half of the fissure, in caries infiltrant + flowable composite group, all specimens showed dye penetration into the sealant, but not over the infiltrant. Conclusion: Using caries infiltrant as sealing material under a flowable composite cover is effective to improve the immediate sealing ability in carious fissures compared to sealing with flowable composite.

Keywords: Dental Materials; Pit and Fissure Sealants; Dental Caries; Dental Leakage.
\end{abstract}




\section{Introduction}

Sealing pits and fissures surfaces with a thin layer of resin was introduced as a caries preventive method in the late 1960s, with the advent of enamel etching techniques and Bis-GMA resins [1]. Dental sealants are used as a permanent superficial mechanical barrier between the enamel surface and the pathogenic biofilm. There is strong scientific evidence suggesting that resin-based fissure sealants are effective in preventing occlusal caries in permanent molars of children and adolescents compared to non-sealed teeth [2]. The caries-preventive effect of sealants ranges from a relative risk reduction in establishment of new carious lesions of $87 \%$ after 12 months to about $60 \%$ after $48-54$ months, depending on the rate of sealant retention $[3]$.

Nowadays, indications for sealing occlusal surfaces have been extended to include carious fissures, since the reduction of viable microorganisms within the sealed fissure will eventually arrest the carious process $[4,5]$, as demonstrated by recent clinical trials [6-8]. In fact, indications for placement of occlusal sealants have shifted from primary prevention to a therapeutic decision for caries management [9,10]. However, it is known that the sealing efficacy of resin-based materials in carious fissures is compromised, compared to sound fissures, due to insufficient sealant penetration and higher prevalence of marginal leakage [11]. In this case, gaps at the interface between the sealant and the tooth may lead to bacterial colonization, thereby hindering arrest of the carious lesion beneath the sealant [12] and up to date, sealants placed over carious lesions in permanent teeth still present lower success rates than conventionally placed restorations [13].

Infiltration of enamel caries with low viscosity resins have been introduced with the aim of arresting non-cavitated lesions by impregnation of the porous enamel lesion, blocking the diffusion pathways for cariogenic acids, thereby reducing or avoiding caries progression [14-16]. Compared with conventional sealing, in caries infiltration, the diffusion barrier is shifted from the enamel surface to the lesion body itself, whereby the progression of the caries lesions is lowered or even arrested [17].

Although primarily indicated for non-cavitated approximal lesions, recently, the caries infiltration technique has been tested in occlusal enamel caries in vitro. In fact, in occlusal enamel showing distinct visual changes related to caries, conventional fissure sealing results only in superficial resin penetration into the lesion body compared to resin infiltration [18]. However, the clinical use of a resin infiltrant as sealing material on the occlusal surface is impaired by its lack of wear resistance [19].

Considering that deeper penetration of a resin-based material in carious fissures may improve sealing efficacy, the aim of this study is to compare the immediate microleakage of carious fissures sealed with a flowable composite to carious fissures sealed with a caries infiltrant covered by a flowable composite.

\section{Material and Methods}

\section{Specimen Preparation and Selection}

From a pool of extracted carious third molars, donated from patients after written consent, 40 specimens were selected and stored in $2 \%$ thymol until used. An initial selection of specimens was performed by visual examination without magnification. The inclusion criteria consisted on the presence of suspected non-cavitated occlusal caries lesions. Severely cavitated carious elements, or those presenting sealings/restorations were excluded, as well as those showing signs of hypoplasia. The selected teeth were cleaned with ultrasonic tips to remove dental calculus and biofilm accumulation. After that, they were mounted by the roots in gypsum blocks and were randomly numbered. 
All the specimens were then scanned in a high energy micro-CT (1173, Bruker micro-CT, Kontich, Belgium) using the following acquisition parameters: $70 \mathrm{kV}, 114 \mu \mathrm{A}$, pixel size $7.12 \mu \mathrm{m}$, sensor $2140 \mathrm{X} 2140$ pixels, $1 \mathrm{~s}$ exposition time, $0.5^{\circ}$ rotation step in $360^{\circ}$ and 20 lines amplitude random movements. A 1 mm-thick aluminum filter was used to remove low energy x-rays to reduce artefact formation. Reconstruction into crosssection images was performed by means of proprietary software (Nrecon, v.1.6.9.4, Bruker micro-CT, Kontich, Belgium), using the following parameters: ring artefact correction (5), beam hardening correction (75\%) and standardized contrast limits between o e 0.1. After visual analysis of the whole specimen volume (DataViewer, Bruker micro-CT, Kontich, Belgium), each tooth was classified according to the caries progression scores described in Figure 1.

\begin{tabular}{|c|c|c|}
\hline $\begin{array}{c}\text { Caries progression } \\
\text { scores }\end{array}$ & Description & $\begin{array}{c}\text { Representative micro-CT } \\
\text { images }\end{array}$ \\
\hline E0 & $\begin{array}{c}\text { No signs of enamel or } \\
\text { dentin demineralization }\end{array}$ \\
\hline E1 & $\begin{array}{c}\text { Enamel } \\
\text { demineralization, } \\
\text { without cavitation }\end{array}$ \\
\hline E2 & $\begin{array}{c}\text { Enamel } \\
\text { demineralization and } \\
\text { surface cavitation. No } \\
\text { dentin demineralization }\end{array}$ \\
\hline D1 & $\begin{array}{c}\text { Demineralization } \\
\text { affecting the outer half } \\
\text { of dentin }\end{array}$ \\
\hline D2 & $\begin{array}{c}\text { Cavitated dentin lesion } \\
\text { Demineralization } \\
\text { affecting the inner half } \\
\text { of dentin }\end{array}$ \\
\hline
\end{tabular}

Figure 1. Caries progression scores attributed to the specimens after micro-CT scanning and reconstruction.

Specimens classified as D3 were excluded from the initial sample $(n=16)$ as conventional restorative treatment is normally indicated in these cases, rather than sealing [20]. Sound specimens (E0) were also excluded $(n=4)$. The remaining specimens $(n=20)$ were paired according to the respective caries progression scores. The division of the specimens among the groups is shown in Table 1. Experimental groups $(\mathrm{n}=10$ each) were then divided according to the following sealing techniques:

- Flowable Composite: The occlusal surface was conditioned with 37\% phosphoric acid (Condac 37, FGM, Joinville, Brazil) for 30s, washed with water for the same period and dried. A conventional 2-step adhesive was applied with a microbrush (Single Bond, 3M ESPE Deutschland GmbH, Seefeld, Germany) and lightcured for 20s. After that, a flowable composite (Z350 flow, 3M ESPE Deutschland GmbH, Seefeld, Germany) was applied with the aid of an explorer and light-cured for 40 s. 
- Resin Infiltrant + Flowable Composite: The occlusal surface was conditioned with 15\% hydrochloridric acid (Icon Etch, DMG America, Ridgefield Park, NJ, USA) for 2 minutes, washed with water for 30s and dried with compressed air. After that, Icon Dry (DMG America, Ridgefield Park, NJ, USA) was applied for 30s. The resin infiltrant (Icon, DMG America, Ridgefield Park, NJ, USA) was then applied and light-cured after 40s. A flowable composite (Z350 flow, 3M ESPE Deutschland GmbH, Seefeld, Germany) was applied over the applied infiltrant layer with the aid of an explorer and further light-cured for 40 s.

Table 1. Paired specimen distribution according to caries progression among the experimental groups.

\begin{tabular}{lccccc}
\hline \multicolumn{1}{c}{ Groups } & \multicolumn{5}{c}{ Micro-CT Scores for Caries Progression } \\
& E1 & E2 & D1 & D2 & Total \\
\hline Flowable Composite & 1 & 3 & 3 & 3 & 10 \\
Icon + Flowable Composite & 1 & 3 & 3 & 3 & 10 \\
\multicolumn{1}{c}{ Total } & 2 & 6 & 6 & 6 & 20 \\
\hline
\end{tabular}

After completion of sealing procedures, the specimens were stored in distilled water for $24 \mathrm{~h}$ and were then subjected to a microleakage assay by immersion in $3 \%$ methylene blue during $24 \mathrm{~h}$ at $24^{\circ} \mathrm{C}$. After that, they were washed in distilled water for $30 \mathrm{~min}$ and serial sectioned by the crown in the mesio-distal direction with the aid of a $300 \mu \mathrm{m}$-thick diamond disk in a cutting machine (Isomet, Buehler Ltd., Lake Bluff, USA). Each specimen was cut in five sections of approximately $1 \mathrm{~mm} \pm 0.2 \mathrm{~mm}$ thickness, which were evaluated in a stereomicroscope at $25 \mathrm{X}$ magnification.

Microleakage scores were attributed independently by two calibrated evaluators. A calibration session was undertaken where a senior researcher presented the scores (Figure 2) and discussed with the evaluators the specific criteria for each. During the evaluation, the sections were divergence on the scores were noted, a new score was attributed after discussion and consensus between the evaluators and the senior researcher. A total of 120 sections were analyzed and, from the scores attributed to each tooth, the most frequent value (mode) was considered as the unique value for the specimen. The total number of sections analysed allowed a statistical power of $80 \%$. For statistical analysis, binomial tests were used to test differences between two independent sample proportions for each attributed scores in each group. The significance level selected was $5 \%$ and all statistical calculations were performed with the aid of BioEstat 5.3 software (Instituto Mamirauá, Manaus, AM, Brazil).

\begin{tabular}{|c|c|c|}
\hline $\begin{array}{c}\text { Microleakage } \\
\text { scores }\end{array}$ & Description & Representative images \\
\hline 0 & No dye penetration \\
\hline 1 & $\begin{array}{c}\text { Penetration of dye } \\
\text { up to half of the } \\
\text { fissure }\end{array}$ \\
\hline 2 & $\begin{array}{c}\text { Penetration of dye } \\
\text { up to the full depth } \\
\text { of the fissure }\end{array}$ \\
\hline
\end{tabular}

Figure 2. Microleakage scores used in the present study. 


\section{Ethical Aspects}

All procedures were conducted in full accordance with the World Medical Association Declaration of Helsinki and this research protocol has been independently reviewed and approved by the institutional ethics committee (CAAE 54270016.3.0000.5257).

\section{Results}

Table 2 shows the quantitative distribution of microleakage scores for each experimental group. When a flowable composite was solely used over the carious occlusal surfaces, a higher prevalence of microleakage scores 2 (penetration of dye along the full depth of the fissure) was observed, compared with the combined use of the resin infiltrant and flowable composite $(\mathrm{p}<0.05)$.

Table 2. Distribution of the specimens in relation to mode values for microleakage scores.

\begin{tabular}{ccccc}
\hline Groups & \multicolumn{4}{c}{ Microleakage Scores } \\
& 0 & 1 & 2 & Total \\
& $\mathrm{N}(\%)$ & $\mathrm{N}(\%)$ & $\mathrm{N}(\%)$ & $\mathrm{N}(\%)$ \\
\hline Icon + Flowable Composite & $3(30.0)^{\mathrm{a}}$ & $5(50.0)^{\mathrm{a}}$ & $2(20.0)^{\mathrm{a}}$ & $10(100.0)$ \\
Flowable Composite & $1(10.0)^{\mathrm{a}}$ & $2(20.0)^{\mathrm{a}}$ & $7(70.0)^{\mathrm{b}}$ & $10(100.0)$ \\
\hline *Different superscript letters in each column indicate statistical significance (Binomial tests).
\end{tabular}

Figure 3 shows the distribution of microleakage scores among each experimental group according to the classification of lesion progression. For specimens showing microleakage scores 1, in the group where carious fissures were sealed with the caries infiltrant and the flowable composite, all specimens showed dye penetration only from the surface to the limit between the flowable resin and the infiltrant, as seen in Figure 4. Thus, although these specimens showed complete penetration of the dye into the sealant, but not over the infiltrant barrier.

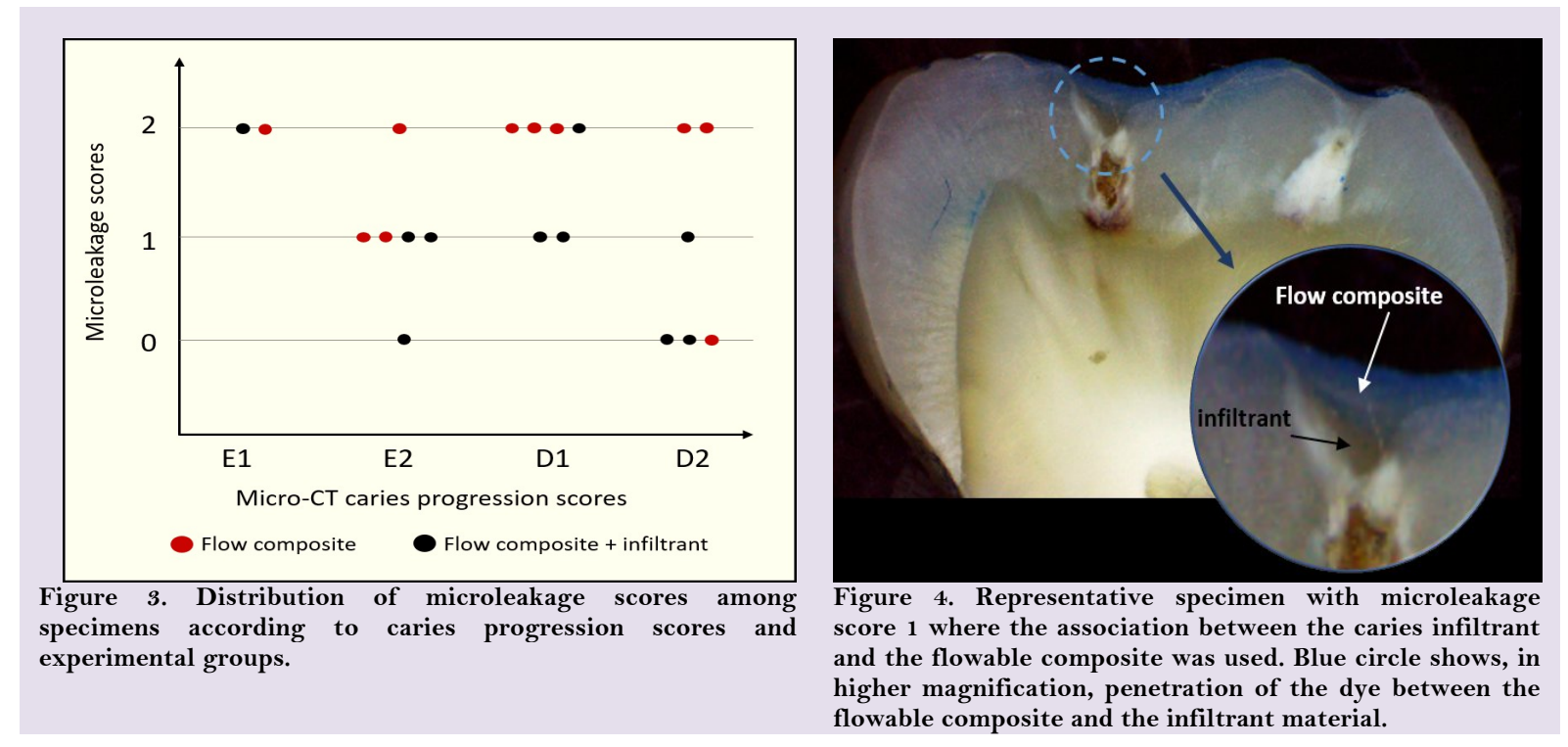

\section{Discussion}

Fissure sealings are certainly effective methods to arrest caries at the enamel surface or those located in the outer surface of dentin [7,9,10,21]. Although it is also nowadays postulated that sealing cavitated 
occlusal lesions result in arrest of the lesion, in this study, specimens showing dentin cavitation were excluded, since these lesions are conventionally indicated for composite restorations [20]. Moreover, to avoid selection bias from using lesions with different severity stages, specimens were paired according to its caries progression scores following a detailed micro-CT evaluation.

The present study has provided microleakage evaluation only 24 hours after treatment and this is certainly one of the limitations of the study. In the clinical scenario, long-term degradation of the interface is most probably accounted for sealant failure and it could be expected that ageing of specimens would result in increased microleakage scores. However, an immediate in vitro evaluation, such as microleakage may be considered as a good screening or a reference towards which different materials and/or combinations of materials should be tested and/or clinically applied [22].

It is known that the effectiveness of a sealing material in caries prevention is related to its complete retention on the occlusal fissure [2,3]. In turn, retention of composite sealing material is directly related to its penetration depth, marginal sealing ability [23] and resistance to wear [19]. It has been shown that the application of a resin infiltrant into occlusal fissures results in higher penetration depth compared to conventional composite sealing material, especially if more severe enamel carious lesions (ICDAS 2) are sealed. Incipient lesions or sound fissures seem not to benefit from the infiltrant material compared to conventional sealing [18]. This corroborates the results of the present study where the use of a caries infiltrant before application of the resin-based sealant resulted in significantly less microinfiltration compared to solely use of the resin-sealant material (Table 2 and Figure 3). Moreover, pre-treatment with hydrochloric acid seems to increase penetration depth compared with the use of phosphoric acid for enamel etching $[8,18]$.

In sound fissures, resin-based sealing materials seem to benefit clinically from pretreatment of the fissures with dentin adhesives [24,25], but this treatment does not increase penetration of the sealant in carious fissures, and in these cases, the incomplete penetration of the material increases susceptibility to infiltration [11]. As adhesive materials do not offer improved penetration in carious fissures and knowing that caries infiltrants are composite materials able to penetrate hundreds of micrometers into porosities of carious lesions [8], in the present study, in order to reduce the microleakage and to improve penetration along carious fissures, the association between the resin infiltrant and a flowable resin was tested against the isolated use of flowable resin for fissure sealing, in vitro. It was postulated that the infiltrant could improve the sealing ability of carious fissures compared to the use of a conventional sealing material. It is, however, expected that clinically, if used without a sealing cover, the infiltrant will not show satisfactorily erosive and wear resistance against occlusal forces [19]. Flowable resin materials, on the other hand, are outperforming conventional sealants in recent randomized clinical trials [26,27]. Thus, a combination of the two materials could certainly increase clinical retention results in vivo.

In the present study, in specimens sealed with the association between the infiltrant and the flowable resin, 30\% did not show any dye infiltration inside the fissure (score 0 ), while $50 \%$ showed dye infiltration until half of the fissure (score 1). But in these cases, infiltration progressed only from the tooth surface until the limit between the flowable resin and the infiltrant. Thus, it can be concluded that in this group, $80 \%$ of the specimens showed appropriate immediate sealing ability, despite of the caries progression stage of the lesion. This corroborates with a recent clinical study, which demonstrated, in vivo, that initial occlusal caries in primary teeth after Icon infiltration also showed a better infiltration and sealing ability of the occlusal fissures, and a significant difference in arresting caries in relation to lesions treated with Duraphat [28]. 
In the group where only the flowable resin was applied, $10 \%$ of the specimens did not show any dye penetration, while $20 \%$ had infiltration up to half of the fissure. Seventy percent of the specimens in this group has shown dye infiltration until the full depth of the fissure, indicating that flowable resin penetration inside carious fissures was probably not to an extent to reach appropriate immediate sealing ability of carious fissures. Sealing carious lesions in both primary or permanent dentitions show already substantial clinical evidence of caries arrestment [6,29] and thus, improving this treatment strategy to optimize longevity of the sealings could be interesting as to reduce costs and maximize the efficiency of minimal invasive interventions.

\section{Conclusion}

Using a caries infiltrant as sealing material under a flowable resin cover is effective to improve the immediate sealing ability of the material in carious fissures compared to sealing with only a flowable composite material. More studies are needed to evaluate the sealing quality of the combined use of caries infiltrants and flowable composites in carious fissure sealing after artificial aging.

\section{Authors' Contributions}

\begin{tabular}{|c|c|c|}
\hline VBS & (iD) $0000-0001-7464-5395$ & $\begin{array}{l}\text { Investigation, Writing - Original Draft Preparation and Writing - Review and } \\
\text { Editing. }\end{array}$ \\
\hline $\mathrm{RNC}$ & (iD) $0000-0001-8871-7193$ & Validation, Formal Analysis and Writing - Review and Editing. \\
\hline TGB & (iD) $0000-0002-5301-8525$ & Investigation and Writing - Review and Editing. \\
\hline TMPS & (iD) 0000-0003-1061-3794 & Methodology and Software. \\
\hline RTL & (iD) $0000-0001-7250-824 \mathrm{X}$ & $\begin{array}{l}\text { Resources, Supervision, Project Administration, Funding Acquisition and Writing } \\
\text { - Review and Editing. }\end{array}$ \\
\hline AAN & (iD) $0000-0002-6049-0588$ & $\begin{array}{l}\text { Conceptualization, Methodology, Data Curation, Supervision, } \\
\text { Administration, Funding Acquisition and Writing - Review and Editing. }\end{array}$ \\
\hline
\end{tabular}

\section{Financial Support}

This study was funded by FAPERJ (E-26/203.185/2016), Coordenação de Aperfeiçoamento de Pessoal de Nível Superior Brasil (CAPES) - Finance Code 001 and CNPq.

\section{Conflict of Interest}

The authors declare no conflicts of interest.

\section{References}

[1] Sanders BJ, Feigal RJ, Avery DR. Pit and fissure sealants and preventive resin restorations. In: McDonald RE, Avery DR, Dean JA, editors. Dentistry for the Child and Adolescent. 8th ed. St. Louis: Mosby; 2004. p.353-363.

[2] Wright JT, Tampi MP, Graham L, Estrich C, Crall JJ, Fontana M, et al. Sealants for preventing and arresting pitand-fissure occlusal caries in primary and permanent molars: a systematic review of randomized controlled trials. J Am Dent Assoc 2016; 147(8): 631-645.e18. https://doi.org/10.1016/j.adaj.2016.06.003

[3] Ahovuo-Saloranta A, Hiiri A, Nordblad A, Makela M, Worthington HV. Pit and fissure sealants for preventing dental decay in the permanent teeth. Cochrane Database Syst Rev 2013; CDoo1830. https://doi.org/10.1002/14651858.CDo01830.pub5

[4] Going RE, Loesche WJ, Grainger DA, Syed SA. The viability of microorganisms in carious lesions five years after covering with a fissure sealant. J Am Dent Assoc 1978; 97(3):455-62. https://doi.org/10.142 19/jada.archive.1978.0327

[5] Jensen OE, Handelman SL. Effect of an autopolymerizing sealant on viability of microflora in occlusal dental caries. Scand J Dent Res 1980; 88(5):382-8. 
[6] Dias KR, Andrade AC, Wait TT, Chamon R, Ammari MM, Soviero VM, et al. Efficacy of sealing occlusal caries with a flowable composite in primary molars: a 2-year randomized controlled clinical trial. J Dent 2018; 74:49-55. https://doi.org/10.1016/j.jdent.2018.05.014

[7] Hesse D, Bonifacio CC, Mendes FM, Braga MM, Imparato JC, Raggio DP. Sealing versus partial caries removal in primary molars: A randomized clinical trial. BMC Oral Health 2014; 14:58. https://doi.org/10.1186/1472-6831-14-58

[8] Lausch J, Paris S, Selje T, Dorfer CE, Meyer-Lueckel H. Resin infiltration of fissure caries with various techniques of pretreatment in vitro. Caries Res 2015; 49(1):50-5. https://doi.org/10.1159/000366082

[9] Crall JJ, Donly KJ. Dental sealants guidelines development: 2002-2014. Pediatr Dent 2015; 37:111-15.

[10] Splieth CH, Ekstrand KR, Alkilzy M, Clarkson J, Meyer-Lueckel H, Martignon S, et al. Sealants in dentistry: outcomes of the ORCA saturday afternoon symposium 2007. Caries Res 2010; 44(1):3-13. https://doi.org/10.1159/000271591

[11] Hevinga MA, Opdam NJ, Frencken JE, Bronkhorst EM, Truin GJ. Can caries fissures be sealed as adequately as sound fissures? J Dent Res 2008; 87(5):495-8. https://doi.org/10.1177/154405910808700514

[12] Kidd EA. Microleakage: A review. J Dent 1976; 4:199-206.

[13] Alves LS, Giongo FC, Mua B, Martins VB, Silva BB, Qvist V et al. A randomized clinical trial on the sealing of occlusal carious lesions: 3-4-year results. Braz Oral Res 2017; 31 :e44. https://doi.org/10.1590/1807-3107BOR-2017.vol31.0044

[14] Meyer-Lueckel H, Bitter K, Paris S. Randomized controlled clinical trial on proximal caries infiltration: three-year follow-up. Caries Res 2012; 46(6):544-8. https://doi.org/10.1159/000341807

[15] Paris S, Bitter K, Naumann M, Dorfer CE, Meyer-Lueckel H. Resin infiltration of proximal caries lesions differing in ICDAS codes. Eur J Oral Sci 2011; 119(2):182-6. https://doi.org/10.1111/j.1600-0722.2011.00807.x

[16] Paris S, Meyer-Lueckel H, Kielbassa AM. Resin infiltration of natural caries lesions. J Dent Res 2007; 86(7):662-6. https://doi.org/10.1177/154405910708600715

[17] Meyer-Lueckel H, Paris S. Improved resin infiltration of natural caries lesions. J Dent Res 2008; 87(12):1112-6. https://doi.org/10.1177/154405910808701201

[18] Paris S, Lausch J, Selje T, Dorfer CE, Meyer-Lueckel H. Comparison of sealant and infiltrant penetration into pit and fissure caries lesions in vitro. J Dent 2014; 42(4):432-8. https://doi.org/10.1016/j.jdent.2014.01.006

[19] Zhao X, Pan J, Zhang S, Malmstrom HS, Ren YF. Effectiveness of resin-based materials against erosive and abrasive enamel wear. Clin Oral Investig 2016; 21:463-8. https://doi.org/10.1007/s00784-016-1814-3

[20] Schwendicke F, Frencken JE, Bjorndal L, Maltz M, Manton DJ, Ricketts D, et al. Managing carious lesions: Consensus recommendations on carious tissue removal. Adv Dent Res 2016; 28(2):58-67. https://doi.org/10.1177/0022034516639271

[21] Bakhshandeh A, Qvist V, Ekstrand KR. Sealing occlusal caries lesions in adults referred for restorative treatment: 2-3 years of follow-up. Clin Oral Investig 2012; 16(2):521-9. https://doi.org/10.1007/s00784-011-0549-4

[22] Pitchika V, Birlbauer S, Chiang ML, Schuldt C, Crispin A, Hickel R, et al. Shear bond strength and microleakage of a new self-etch adhesive pit and fissure sealant. Dent Mater J 2018; 37(2):266-71. https://doi.org/10.4012/dmj.2017-072

[23] Sridhar LP, Moses J, Rangeeth BN, Sivakumar S. Comparative evaluation of the marginal sealing ability of two commercially available pit and fissure sealants. J Clin Diagn Res 2016; 10:ZCo1-ZC4. https://doi.org/10.7860/JCDR/2016/19996.8413

[24] Bagherian A, Sarraf Shirazi A, Sadeghi R. Adhesive systems under fissure sealants: yes or no? a systematic review and meta-analysis. J Am Dent Assoc 2016; 147(6):446-56. https://doi.org/10.1016/j.adaj.2016.01.014

[25] Erbas Unverdi G, Atac SA, Cehreli ZC. Effectiveness of pit and fissure sealants bonded with different adhesive systems: a prospective randomized controlled trial. Clin Oral Investig 2017; 21(7):2235-43. https://doi.org/10.1007/s00784-016-2016-8

[26] Erdemir U, Sancakli HS, Yaman BC, Ozel S, Yucel T, Yildiz E. Clinical comparison of a flowable composite and fissure sealant: a 24-month split-mouth, randomized, and controlled study. J Dent 2014; 42(2):149-57. https://doi.org/10.1016/j.jdent.2013.11.015

[27] Kucukyilmaz E, Savas S. Evaluation of different fissure sealant materials and flowable composites used as pit-andfissure sealants: a 24-month clinical trial. Pediatr Dent 2015; 37(5):468-73.

[28] Bakhshandeh A, Ekstrand K. Infiltration and sealing versus fluoride treatment of occlusal caries lesions in primary molar teeth. 2-3 years results. Int J Paediatr Dent 2015; 25(1):43-50. https://doi.org/10.1111/ipd.12096

[29] Zhang WW, Mulder J, Frencken JE. Is preventing micro-cavities in dentine from progressing with a sealant successful? Br Dent J 2019; 226(8):590-4. https://doi.org/10.1038/s4141 5-0 19-0195-9 